\section{Psychodynamic Formulation in Assessment for Psychotherapy}

$R$ Hinshelwood

What dire offence from amorous causes spring What mighty contests rise from trivial things

SUMMARY. This paper describes one form of psychodynamic formulation. Three areas of object-relations (the current life situation, the early infantile relations and the transference relationship) are focused upon to derive a common pattern. From these core object-relationships a point of maximum pain can be hypothesised and the attendant defensive relationships. The paper also discusses the central importance of testing hypotheses with interpretation even in the assessment interview, and the prime interest of the psychodynamic formulation in assessing other factors in the suitability of a patient for psychotherapy.

In assessing referrals for psychotherapy and psycho-analysis, it is best to avoid the use of the term 'diagnosis' because it becomes confused with psychiatric diagnosis and the medical treatment of patients. Other terms are 'assessment' or 'consultation' or 'initial interview'. They all carry a slightly different emphasis on what we do at that first meeting with a possible patient or client. The reason that there are several terms is that we are engaged on a number of different functions at that meeting, and different therapists give different emphasis to these various functions.

In this paper I want to concentrate on the most important and, I think, the most interesting of these functions, the psychodynamic formulation. Other things will be left aside - the psychiatric diagnosis and the detecting of psychosis, the assessment of suitability for psychotherapy and preparation for psychotherapy. All these last things, in my view, follow on from the clear formulation of the psychodynamics of the case.

It has been said that the process over the course of a whole psychotherapeutic treatment is really one long protracted formulation of the psychodynamics. This initial formulation is a kind of session in miniature. However, we are doing something harder because of the very short time in which to do it, because we want to get out a very broad overview and also because of the often very high levels of anxiety that the patient may bring and communicate. We need to develop a special clarity of thought.

Hypotheses and interpretation: There may be a danger in that my hypothesising about the deepest aspects of these patients, on one interview, will be regarded as much too speculative. However, the nature of psychotherapy is the intuitive production of hypotheses - they are for trying out with the patient. We do not work to build up evidence before making a hypothesis as in other forms of science; in fact the reverse, the process of therapy is to try out hypotheses with the patient. Our evidence comes from watching the fate of our hypotheses. The response to an interpretation is then the criterion for deciding whether to retain the hypothesis or abandon it. And in this way it may be that the cautious procedures of ordinary scientific activity are turned on their head. In my own practice I feel more comfortable with establishing in my own mind a marker of where I am in the material, of finding bearings, of recognising the currents in the interaction that pull or push me. A moment of reflection in the midst of the immediacy is important to achieve, and this is my own method for trying to achieve it. It is my method for achieving what Bion described as "continuing to think when under fire'.

\section{Framework}

To gain this clarity I shall follow a particular framework for thinking about the flow of material in the interview. Briefly it is this. Clinical material is best approached as pictures of relationships with objects. There are then three areas of object-relationships which I try to bear in mind.

(i) the current life situation

(ii) the infantile object-relations, as described in the patient's history, or hypothesised from what is known

(iii) the relationship with the assessor which, to all intents and purposes, is the beginning of a transference.

Such a framework is not original. Karl Menninger (1958) is responsible for making the first clear exposition of this tripartite structure of a psychodynamic formulation. It was greatly elaborated by Malan (1979) and also Molnos (1984). It is in any case implied in the psycho-analytic theory. I want merely to illustrate its usefulness and clarity by following through some examples.

Let us take the three areas - current life situation, infantile object-relationships, and the transference - in order.

\section{The current life situation}

Most patients will start by talking about their current life situation - their symptoms now; their relations with spouses, with work or with parents in the present.

A rather young-looking business man in his mid-thirties was referred because of panic attacks in which he felt convinced he was going to die. He stated that it was due to the stresses hewas under at work; and with encouragement he went on to tell me obout these stressess - he was he attributes the whole of his problem. Fifteen mon to sales project the patient this that the mana who according to the patient, is equally dubious abo now according the patient, is equally dubious about a project he pationt is working on. He now has a time limit to come up with plans for the new project, the staffing etc. and he is very preoccupied by the stress that he is now under.

You can perhaps imagine the pressured way in which this salesman gave his well-rounded summary of what caused his problems. It became necessary to move him on to talk about his family. He talked about his daughter (8 years old) who he tells mis pride he and his wife have in her. There is clearly a strong and, through identification, in his daughter. We can make the hypothesis that there is significant relationship with a powerfully dem. We can make the hypothesis that ther significant relationship with a powerfully demanding figure in the patient's life, goading him

Such an object-relationship is likely to be an internal one as well as the result of an actual external relationship. We might refer to it as a harsh and dominating super-ego. Can we get any confirmation of this? 
To look into his internal objects leads us on to the next man field of objectrelationships, the infantile ones.

\section{The infantile object-relationships}

The actual relationships in infancy are a long time ago. Evidence of them is therefore by inference. We can start by listening to the memories he has retained of his relationships. With the case I have just mentioned, the following emerged:

He described his father as a Victorian who would not listen to others. This was particularly acute when the patient had first gone to work, managing one of his father's shops. As a child, too, he had felt humiliated by his father who intimidated all the other children as well. (He was incidentally the youngest of six, the eldest being more than 20 years senior.) The older brothers and sisters had all given in to father and looked up to him. He alone had not accepted that and sisters had all given in to father and
father simply did not listen to his views.

We have here a relationship with a father, pictured from childhood, that resembles the super-ego figure the patient finds in his current life situation. It is one who is dubious and critical about the patient's abilities and projects, to the extent that the patient feels completely dismissed. The similarity was quite chilling because he showed an obvious and similar pain as he evoked the memory of his father as he told me about him in the session.

When I pointed out the importance in his life of this dismissive and demanding figure, his response was interesting - there was, first, a denial and then an unconscious confirmatio which took us a step further in understanding his make-up. First he referred once again to his current life situation - he kept on going back to this in the interview. He said he understood the point I was making about the similarity between working for his father and, later, working for the other managers, but he did not think it affected the rest of his life - that was the denial. His need for praise and approval was simply in his work

Now, the interesting thing is that his next thought deviated from his repetitious interest in his work. He told me, for the first time, of his unreasonable jealousy that his wife would not be faithful to him. He had no reason to believe that.

The association about an unreasonable degree of jealousy actually confirmed something that had been hovering into focus in my mind. I found I had been describing in my own mind an insecure man, one very much in need of reassurance in all areas of his life, not just his work; in fact much more than the restricted work situation which was all that he could admit to me and probably all he could admit to himself. Something inside him also demolished his belief in himself as a husband as well as a manager at work. His admission of an irrational jealousy of his wife confirmed my impression that the experience of father and, subsequently, unimpressed employers was continuous with a 'general' internal process of demolition, a super-ego that was primitive to the point of being an internal persecutor. Some people might call it an internal saboteur.

\section{Transference}

Now, turning to the third area of object-relationships, the transference, in my notes on the assessment session with this patient there was the following comment: " $H$ e spent quite a lot of time going over, somewhat repetitively, the ins and outs of the work situation. He talked about it in a business-like manner, as if presenting a file on a problem at work'. The indication is clear; he was presenting himself as if to a manager at work. I appeared before him as the father/employer who might dismiss him and from whom he vainly sought approval - the demanding and unrelenting super-ego figure internally. My point here is that the third area of object-relationships, the rapport in the assessment interview is in accord with the relationships emerging from the other two areas.

$$
\text { The core object-relationship }
$$

I am picking out as a common theme a typical relationship that runs through all three areas of this patients life - the current life, the infantile relationships, and the transference. The critical managers at work who were dubious about him reflect the experience of a critical and domineering father in his childhood because he has formed and retained that sort of internal figure he has formed and retained that sort of internal figure inside him, and he then projects that figure on to me in the interview. Why he did form that sort of internal figure may be to do with the character of his actual father, though it may well be to do with factors internal to his own character as well. Why he continues to retain that figure as an internal, demolishing persecutor must really be to do with factors inside him which are yet to be discovered and would be the work of psychotherapy.

\section{The internal parent/child relationship}

I will give another patient's assessment session as a further illustration of the way these three areas of object-relationships fit together. This again concerns disturbed parent/child relationship. The inter-relationship of these two figures parent and child-is a little more complicated than in the previous example. It may help to bear in mind the notion of an internal child (the child part of the patient), and an internal parent (that is, the patient's ability to be a parent) and a relationship between the two. And, in addition, the possibility that this relationship could be acted out with external figures through externalising one or other of these two internal figures - that to say, either the patient can feel a child in relation to an external parent, as in the case of the patient I have just described; or the patient can feel a parent in relation to external figures into whom she has externalised her own internal child part (the external figures, in the case I am about to describe, being her own children).

\section{The current life situation}

This was a 35-year-old woman who initially presented with a curiously distracted look and an irritatingly haughty middle-class manner. She talked in a baby-like voice and told me little until she said she had to keep up a front because she did not want people to know about her. When I asked why that was, in perhaps a rather sympathetic way, she suddenly cried ant her. rapport changed completely to a trusting and engaged manner.

So far as the current life situation is concerned, she is frequently depressed and especially so after the births of her two children, one aged 4 years and one aged 5 months. She feels, painfully, the demands that her husband makes on her. He insists on a particular, dislocated ife-style unaffected by the arrival of the children. During the weekdays, he expects her to accompany him to their flat in Chelsea. There they both have jobs and a social life. She leaves the children in the care of a nanny in their country home. She acquiesces in this though she is not in agreement with it. She feels helpless to do anything about it and is unable to protest to her husband as she does not feel she can burden him with the unhappiness of this arrangement. Instead she was unreasonably nagging with the nannies. They therefore frequently left. There is 
here a sad picture of neglected children and a helpless mother, aware of the situation but unable to do anything about it.

The infantile object relationships

Then, looking into her infantile object-relationships, something emerged which was quite similar in pattern although it appeared the other way around to the current life situation. I learned that in her childhood she had had a somewhat idealised view of her father until, at the age of 8 , she was told that she was actually illegitimate and that he was in fact her step-father. From then on she was very unhappy and could not wait to get away to her boarding school at age 11 . Here there is again a situation in which nothing can be done apparently for the child whose disappointment with her parents is nothing can be done appar something else. In her adult catastrophic, so that she can only get away to someone or something else. In her adult to turn to.

\section{Transference}

Now, about the transference - a strikingly similar, and unfortunate, occurrence took place at the end of this one assessment session. She actually knew very little about psychotherapy and I spent some time explaining things to her, in the course of which 1 psealised that she was expecting to continue to see me. I should have explained to her at the outset that it was simply an assessment session and that, if we decided that psychotherapy was suitable, I would recommend a suitable colleague to her. When I did tell her that I would not personally be treating her, there was a catastrophic reaction.

It is important to be very clear at the outset, and even on the telephone when the interview is set, that it is to clarify the person's needs and to find a suitable therapist if necessary. I had made a mistake here. It might have been an innocuous one but the specific traumatic reaction of this patient to my mistake was highly illustrative in itself of the patient's difficulties.

She went very quiet, and it emerged that she was very put out. She complained that she should have been told that she was being sent to be 'evaluated'. She was insistent on terminating the interview then and there, and departed angrily and somewhat grandly demanded that whoever I recommended her to see should contact her. (Incidentally, she did start in therapy with someone else, and is apparently doing well.)

There is an important similarity to note: the catastrophic news that her father was not her real legitimate father and the news that I would not be the real therapist; and there is also the similarity between the escape to the boarding school and the escape to the new therapist. The hypothesis that came naturally to mind was that the idealised position she established for me early in the session, as someone she could allow to know about her - she could let me see her tears - was catastrophically shattered; and if this were so it was exactly reminiscent of the revelation about her step-father, and her impulse was to get away to the next therapist (equivalent to the boarding school). This is a strong hypothesis because it allows us to match up various object-relations: (i) the shattered children she supposed (perhaps rightly) she left in the family home in the country; (ii) the shattered idealisation of the father she had suffered as a child, in the country, (Ii) the shatte (iii) her shattered idealisation of myself in the transference. infantile situation; and (iii) her shattered idealisation of myself in the transference. Each of these object-relationships called out a specific response, moving away - to the boarding school, the next therapist, or the sophisticated life in Chelsea.

Incidentally, we can note that, in her current life situation, the demand to escape to Chelsea was attributed to her husband. But we can see that it is really part of the characteristic object-relationship externalised into the husband; this part of the relationship is an internal demand to escape the experience of the shattered child.

In the different areas of object-relationships different internal figures are externalised. In the infantile situation she is identified with the shattered child and externalises the inadequate parent into her father; and this was repeated in the transference. However, in the current life situation, the shattered child part of her is externalised into her own children - probably meeting a reality which conforms to this projected expectation. This makes the formulation a little complicated. But we can keep it clear if we hold in mind a single picture of a relationship with an object; and then we can follow which bits get projected or which get identified with.

Also in this case we have both the problem area, the inadequate parenting of a shattered child, and the escape from this. I will return to this defensiveness in a moment.

\section{The base-line hypothesis}

I have tried to show, so far, with these two illustrations how we can pick out a common theme, by attending to three separate areas of object-relationships. If it is possible to achieve this we can have some confidence that the theme represents some approximation to an internal object-relationship, lived out continually and repeatedly, in the long term of the patient's life. In fact, in the second case, we could have become sidetracked into too narrow a view, if we did not look at all these various aspects of the patient's history. For instance, initially one might have been tempted to become concerned with the relations with her father based on her presentation, that is, the experience of having an uncomprehending husband.

However, if we consider carefully all the areas of object-relationships, this would be too narrow a view of the maternal and paternal figures in the actual parents. To the catastrophic disappointment with the father, we must add the evidence of the current life situation. It is not just the loss of the father. The patient is clearly concerned that her own children are missing her as mother. Thus we can wonder about the father as someone who takes mother away. That is it is an illegitimate parental couple - not just the father.

By keeping in view the depression about employing nannies there is a much more extended function of parenting than just that of the stereotyped father role. In taking all three aspects of the object-relationships into account we can be very much better guided; and are directed in fact towards the maternal transference - a mother who cannot provide properly.

Thus we are able to extend and deepen the hypothesis. It may be a rather tentative hypothesis, but it is in the nature of the formulations made in assessment that they are hypotheses, to be confirmed later by the actual psychotherapeutic work. It forms a baseline on which the future work can be grounded and guided.

$$
\text { The point of maximum pain }
$$

I have described how we can define this core object-relationship and its importance in focusing us in the right direction. We can look at it another way. The importance of 
that object-relationship is that it points directly to a core of pain which the patient is attempting to deal with. I find it is important to formulate what might be called the point of maximum pain; that is to say the particular pain which is involved in the objectrelationship. What follows from that are certain other kinds of object-relationships used to evade that pain (the defences). We then have a way of ordering the various objects and the various relationships into a coherent narrative.

In the first case the man's relationship with his father was painful because there was no 'room' for him to experience himself as growing up, substantial, and with opinions and projects of his own. That object-relationship was the point of maximum pain which he lived out in a restricted way, encapsulated in his work. This called out a further object-relationship which he strove for in order to ameliorate the pain. Instead of giving in to father and looking up to him as he said his brothers and sisters did, he took a defiant and aggrieved attitude. He felt wrongly treated and attempted a moral supremacy.

In the second case, the object-relationship was with a mother who failed repeatedly to sustain the patient's idealisations of herself and her mother, in consort with an idealised father, and thus constantly left the patient feeling catastrophically deflated. In defence she developed a form of escape - distanced relationships in which she remained remote from, and complaining about, denigrated mother substitutes. This was exemplified in the object-relationship as an aloof, vacuous and haughty manne which attempted, rather unsuccessfully, to belie her inner deflation, emptiness and babylike dependence. This opening gambit in the interview was unsuccessful and short-lived; she broke into tears and established another object-relationship with me, which appeared to be characterised by an idealisation of me to whom she could be permanently attached. This idealised relationship was, like the self-idealised haughtiness before it, a constructed relationship with an object designed, not found, which would give respite from the sense of an abandoning object.

These core object-relationships pinpoint the focus of maximum pain, and then make sense of the way in which other object-relationships are used in the attempt to evade the pain.

\section{Transference and counter-transference}

A further matter of great importance, even in the assessment interview, is the counter-transference. As in psychotherapy itself, the counter-transference is a potentially sensitive indicator of the transference. In the cases I have described a counter-transference is noticeable and informative through what it made me do. In the first case, the man's repetitive talking made me 'want to move him on' and, in fact, to do just that; I was then acting in the role of his manager/father who did not respect his own projects. In the second case I found myself disliking this woman's haughtiness and the superior distance she created. However, I also noticed the babylike voice and found myself reacting so sympathetically that she suddenly broke into tears; I was thus attempting, without in any way realising it yet, to be motherly to her in a way that bettered her own parents, external and internal, and thus to go along with the eager idealisation.

These object-relationships, in the form of transference, may often be discerned before the interview, in themanner of the referral itself. Thus, the referral is often made on the basis of the referer's unconscious awareness of a specific relationship. It is a kind of 'acting-out' on the part of the referer who is caught up unconsciously in one of these object-relationships I have been describing. This is not to the discredit of the referer as the awareness of these kinds of relationship is not his field of work and expertise. It is ours. But it is an added clue for us to the patient's core object-relationships - a sort of fourth area on top of those I have described.

This may be apparent even from the referral letter. One letter from a general practitioner came into a hospital department. There was a noticeable stress on the patient's wish to talk about things. This indicates - what? On the surface the patient wants to reflect. However, why stress it? Is he conveying some unconscious awareness of the patient's use of expulsive mechanisms - getting something out of her?

The patient, in her early twenties, was anorexic and had been so for some years in spite of several therapeutic interventions. The only amelioration according to the letter was when the patient left home about a year ago. Relief, the letter seemed to indicate, was gained by distance from an intrusive mother. But recently the patient had started to induce vomiting and her weight had gone down again - whilst the patient was still away from the mother - the assumed pathogen.

What happened at interview was remarkably interesting in the light of this. The young doctor conducting the assessment was in fact overwhelmed by the patient's persistent talking, in immense detail, about her daily weight fluctuations over the preceding years. He found the experience disagreeable and tedious and, although doubtful of psychotherapy, felt obliged to see the patient for more sessions in order to somehow fill in his meagre knowledge of the rest of the patient's life. Thus the referer's apparently optimistic signal that the patient liked to talk was, at a conscious level, misleading - but unconsciously was pointing to a problem. The talking was thus a form of vomiting activity which was designed to eliminate any intrusion, and prevent any headway against this flood of vomit. The referral itself represented a relief for patient and doctor through putting distance between the intrusive parental figure (the doctor) and the patient.

The young doctor's strong experience is eloquent - as eloquent as the GP's letter. In a sense his wish to get more details were quite wrong. It was a desperate attempt, in his inexperience, to do something. He felt flooded, not on top of this case at all and in need of some further effort which he could not really formulate. In fact, he already had the important detail that mattered - the patient's intense fear of intrusion and her desperate defence against it. This was already hinted in the referral letter. Though couched in a professional rationalisation, that the patient wished to talk, it is a clue to help the interviewer get his bearings when overwhelmed.

\section{Conclusions}

Assessments should be no less psychodynamic than psychotherapy itself. From the formulation other aspects of an assessment naturally emerge, the degree of insight and motivation, and the level of maturity of the personality.

One important point to address is whether to make an interpretation in the course of an assessment, a trial of interpretation we might call it. Clearly a psychodynamic formulation puts one in a very good position to make an interpretation, and even a transference interpretation. The interview conducted in this way is a kind of minisession. The kind of response, unconscious as well as conscious, to an interpretation is, in my view, extraordinarily productive as a way of (i) assessing the suitability and psychological-mindedness of the patient, and (ii) the best form of preparation for psychotherapy since it is giving a taste of the real thing.

But problems are raised about this: Are you not starting the patient on a deep 
involvement with yourself, if you are intending to pass on the patient to someone else? or if you decide against suitability for psychotherapy? And, indeed, I have indicated that one has to be very careful about this. Some people think that this is a compelling contra-indication against making interpretations in the assessment interview.

There are, however, two equally compelling arguments for making interpretations. Firstly, an interview with a psychotherapist is already an extraordinary experience for a potential patient, even before he has got to the doorstep. He is deeply involved, in phantasy, with the figure he believes you will turn out to be. It is not in fact an interpretation that starts the deep involvement with you. It has started long before the meeting. Secondly, a point made by Nina Coltart (1988) is that the interview may be the most momentous occasion in the patient's life; the experience of being listened to intently and exclusively may be quite unique, and the chance is that a profoundly positive and idealising relationship will develop on this basis - without making interpretations. The effect of interpretation is to draw attention to those aspects of the patient of which he is unaware and of which, on the whole, he wishes to remain unaware. Thus interpretation, when it comes, is not in any way likely to enhance the personal tie to you. It may confront and even affront. 'It facilitates' to use Nina Coltart's words, 'the patient leaving you without too much regret' (1988, p. 131). In other words an interpretation that grasps the uglier, unconscious aspects of the patient, as well as the positive ones presented to you, will, like Strachey's mutative interpretation, tend to correct the primitive aspects of the patient's relationship and help him towards a more balanced frame of mind towards you. I have intended to emphasise the importance of the psychodynamic formulation above other aspects of the assessment, and also to convey that this is of the greatest interest and fascination as well.

\section{ACKNOWLEDGEMENTS}

I want to acknowledge the helpful comments Julian Kent made on an earlier draft of this paper. Versions of it were given to meetings of the London Centre for Psychotherapy in 1988 and of the Institute of Psychotherapy and Counselling (WPF) in 1990.

\section{References}

Coltart, N. (1988) Diagnosis and assessment for suitability for psycho-analytic psychotherapy. In British Journal of Psychotherapy 4, pp. 127-134.

Malan, D. (1979) Individual Psychotherapy and the Science of Psychodynamics. London: Butterworth.

Menninger, K. (1958) Theory of Psychoanalytic Technique. London: Imago.

Molnos, A. (1984) The two triangles are four: a diagram to teach the process of dynamic brief psychotherapy. In British Journal of Psychotherapy 1, pp. 112-125. 